\title{
A FRAMEWORK FOR CALCULATING THE RELATIVE WEIGHT OF EDUCATIONAL BUILDINGS' CRITERIA
}

\author{
Abdelazeem S. Abdelazeem \\ Assistant Professor, Department of Construction Engineering and Utilities, \\ Faculty of Engineering, Zagazig University, Egypt
}

\begin{abstract}
Ahmed H. Ibrahim
Professor, Department of Construction Engineering and Utilities, Faculty of Engineering, Zagazig University, Egypt

Mohamed S. Mohamed

M.Sc. Student, Department of Construction Engineering and Utilities, Faculty of Engineering, Zagazig University, Egypt
\end{abstract}

\begin{abstract}
Management of educational building assets is one of the most complicated factors because it has a bigger number of related and unrelated criterions. Analytic hierarchy process (AHP) as a decision-making technique is widely deal with many decision problems that have bigger number of criterions. This paper proposes AHP method to define the judgment matrix of related and unrelated criterions that is used to calculate the relative weights ( $R W s$ ) of each criterion. Analytic network process (ANP) was also used to calculate the RWs of the interrelated building categories (architectural, mechanical, and electrical). Such RWs can be used by managers for physical condition assessment of an educational building. The educational building hierarchy are divided into five levels. Each level is then defined in a judgment matrix to calculate its RWs. Then. The consistency of such judgment matrix has been evaluated to ensure that the $R W S^{\prime}$ results are acceptable. As concluded in the space level of the building hierarchy, the classroom space type that includes most of the education processes had the highest relative weight $(R W=26.76 \%)$ followed by the bathrooms $(R W=26.14 \%)$ and corridors and stairs $(R W=25.77 \%)$. On the other hand, the cafeteria space type was the least relative weight $(R W=1.58 \%)$ among all other space types. AHP technique provided an improved approach to calculate the $R W$ s of each criterion affecting physical condition of educational building in Egypt.
\end{abstract}

Keywords: Building; condition assessment; Educational; Relative weight; Facilities management; Analytical hierarchy process; Analytical network process 
Cite this Article: Abdelazeem S. Abdelazeem, Ahmed H. Ibrahim and Mohamed S. Mohamed, A Framework for Calculating the Relative Weight of Educational Buildings' Criteria, International Journal of Civil Engineering and Technology, 12(1), 2021, pp. 48-62.

https://iaeme.com/Home/issue/IJCIET?Volume $=12 \&$ Issue $=1$

\section{INTRODUCTION}

An educational building is an institute designed and built for teaching students. There are many educational facility types such as child development centers, elementary schools, secondary, schools, college, and higher education (Eweda 2012). Certainly, clean, quiet, safe, and comfortable environments are important for teaching and learning to take place in the educational building (Schneider, 2002). Management of educational buildings is one of the most puzzled factors because it is more complicated than other systems with a small number of elements (Elhakeem and Hegazy 2005). Building facilities are considered a main part in the urban infrastructure because they provide accommodation and physical support services for human activity (Eweda 2015). It is not a simple task to manage educational buildings with big number of components and lack of funds. Lack of funds and mismanagement causes deterioration and unsatisfactory situation (Hudson et al. 1997). In order to maintain the great historical, cultural, and economic importance of the educational buildings; the project manager should rank the relative weights of each criterion.

Identifying the most important criteria affecting the physical condition of an educational building is the key to develop an efficient maintenance and repair plan. Also, identifying the most important criteria becomes the first point in a process to develop the guideline of decision making in the future planning and implementation of maintenance. The results of periodic assessment of the most important criteria affecting the physical condition of an educational building are used to predict the deterioration that will happen in the future.

Urquhart et al. (2005) introduced a research stating that asset management is established on an assessment that can reflect assets' current serviceability and failure risk as well as quantify their current value. Thus, a framework for assessing the RWs of criteria affecting physical condition of educational buildings can be used by facility managers for: (1) assessment of the physical building condition; (2) forecasting of the future weakness or deterioration; (3) selecting of maintenance and repair plans; (4) condition improvement after repairing process; and (5) asset prioritization due to lack of funds.

Lack of funds is one of the main reasons causing unacceptable performance of building assets. Maintaining a building is essential to keep it performing and functioning for a longer period of time, and condition assessment is the most important stage during the asset management process. It is crucial to determine when and where it is necessary to repair and rehabilitate any component in the building (Eweda 2012). Over the past years, emphasis has been placed on new construction, without enough attention to the operation costs of existing buildings and proper maintenance (Johnson and Clayton 1998). (Douglas 1996) compares the performance of buildings that degraded during time, with the required performance by users that increase during time. Maintenance and repair (MAR) are required to restore the performance and quality of degraded buildings. MAR of educational buildings will provide optimal quality and economy. Therefore, the purpose of this paper is to calculate and prioritize the criteria affecting physical condition assessment of educational buildings using AHP and ANP techniques. Also, facility managers should contribute to create a healthy and living environment for building users through realizing the most important criteria affecting the physical condition of an educational building. 


\section{LITERATURE REVIEW}

Building performance used to represent the physical performance characteristics of a building as a whole and of its parts (Clift 1995). Also, building performance relates to a building's ability to contribute to fulfilling the functions of its intended use (Williams, 1993). Therefore, the building performance can be enhanced through identifying, assessing, and ranking the RWs of criteria affecting the physical condition of the educational buildings. According to (Rugless 1993), condition assessment (CA) defined as "a process of systematically evaluating an organization's capital assets in order to project repair, renewal, or replacement needs that will preserve their ability to support the mission or activities they were assigned to serve." It was reported in literature that there are several developed condition assessment and rating models such (Elhakeem and Hegazy 2005), they developed a system to enhance the process of the visual inspection of buildings.

Urquhart et al. (2005) conducted a study stating that proper asset management is based on a condition assessment that can reflect assets' current serviceability and failure risk as well as quantify their current value. Thus, calculation of RWs for each criterion can provide a powerful tool to develop building management system that results proactive maintenance and balanced plans (Eweda 2015). Also, Langevine (2006) developed an approach to assess the condition of building components. Also, Ahluwalia (2008) developed an integrated framework for inspection and CA that consists of three main components: (1) condition prediction and inspection planning; (2) a visual guidance system in which a pictorial database supports the visual inspection of building components; and (3) location-based inspection with a standardized building hierarchy. Finally, (Eweda 2015) developed an integrated condition assessment model that take into consideration the physical and environmental condition of an asset. According to previous sources in literature, calculation of RWs for the criteria affecting the physical condition is the most important function throughout the entire asset management system; this is because the results of calculation of RWs for the criteria will help in determining maintenance priority for the educational buildings.

Therefore, the main purposes of identifying the most important criteria are to cover the following characteristics: (1) assessment of the physical condition; (2) prediction of the future deterioration; (3) selection of maintenance and repair plans; (4) condition improvement after repair; and (5) educational building prioritization and fund allocation due to lack of finance.

\section{AHP TECHNIQUE}

Analytical hierarchy process (AHP) was introduced by (Saaty 1980) that is a mathematical technique for multi-criteria decision making. This technique is based on pairwise comparison matrix. AHP is a multi-criteria decision-making technique that can help express the general decision operation by decomposing a complicated problem into a multilevel hierarchical structure of objective, criteria and alternatives (Sharma et al., 2008, Gorener, 2012). AHP technique makes pairwise comparisons or judgment matrices to assess RWs of the elements in each hierarchy level. Also, it appraises the alternatives in the lowest hierarchy level to make the best decision among criteria. Also, AHP technique is an effective decision-making method to solve subjective problems where the decision criteria can be structured into sub-criteria in a hierarchical way (Tuzmen and Sipahi, 2011; Gorener, 2012). AHP technique provides the goals mathematics to process the obviously subjective and personal preferences of the decision maker in making a decision (Saaty and Vargas 2001; Sangiorgio et al. 2018). Also, AHP technique is mainly depending on the decomposition of the problem into independent criteria. Every criterion is examined individually to find the weight assigned to it (Saaty and Vargas 2001). AHP technique uses the principal eigenvalue method for calculating the weight assigned to each criterion from positive reciprocal matrices, which particularly called judgment matrices or 
comparison matrices and they are established through pairs of comparisons (Barzilai et al. 1987; Saaty and $\mathrm{Hu}$ 1998).

The first step in the AHP technique is to structure the hierarchy that will describe the hierarchical levels of the analysis to be performed. Once the hierarchy is established, pair-wise comparison matrices are made among all the alternatives. With the matrix completed for each of the criteria, calculations can be performed to produce the rankings of the criteria (Eweda, 2012).

\section{ANP TECHNIQUE}

ANP is the general form of AHP technique, which is introduced by (Saaty 1996) in order to solve problems involving interaction and feedback among criteria or alternative solutions (Azimi et al. 2011). ANP technique is a general theory of relative measurement used to derive composite priority ratio scales from individual ratio scales that represent relative measurements of the influence of elements that interact with respect to control criteria (Saaty 1996). The ANP does not need to specify levels in a hierarchy, as in the AHP technique, but rather it uses a network. In other words, the ANP provides a solution for problems that cannot be structured in a hierarchy (Saaty 1996).

\section{AHP APPLICATIONS IN CONSTRUCTION INDUSTRY}

AHP technique has been applied for construction industry areas such as risk management decisions and housing. Subramanyan et al. 2012 designed a model for construction project risk assessment through using an integration of fuzzy set theory and AHP. The goal to use fuzzy set theory was to capture both subjectivity and linguistic terms, while the goals to use AHP technique was applied to weight and prioritize various risk factors. Hyun et al. 2008 tackled performance evaluation of housing project delivery methods through combination of the Delphi and AHP techniques with testing analysis of variance (Darko et al. 2019).

Ahmad et al. (2004) generated a decision support system for contractors to challenge the problem of selecting the most suitable site for residential housing projects. Topcu (2004) proposed an AHP-based decision model to prequalify and select contractors based on preference ranking. (Mahdi et al. 2006) used AHP to design a decision-making model for reducing the waiting time and construction cost for housing projects. The effects of different criteria on the selection of proper housing delivery alternatives were analyzed using AHP, after which sensitivity analysis (SA) was performed to investigate the sensitivity of the final decision to possible changes in judgments. Abudayyeh et al. (2007) employed AHP as a decision-making technique to make contractor prequalification. Specifically, the technique was used to find the relative weights of various prequalification criteria, which were subsequently used to rank contractors to select the top ranked contractor for the project. El-Anwar and Chen (2013) established an AHP model for quantifying and minimizing the displacement distance equivalents for families that are assigned temporary housing following a natural disaster. ElSawalhi et al. (2007) suggested a combination of AHP, neural network (NN), genetic algorithm (GA) and Delphi to analyze and improve the accuracy of contractor prequalification and selection. Sha et al. (2008) used AHP within a modified system to define and measure competitiveness in the construction industry scope. The system can help construction creativities better evaluate their overall performance and improve their competence. The indicators at the different levels of the system were weighted using AHP. El-Sayegh (2009) developed a multi criteria decision support model to assist owners in selecting the most suitable construction firm to deliver a project through the $\mathrm{CM}$ at risk project delivery method. Ali and Al Nsairat (2009) used AHP to develop a green building rating tool. After identifying the green building assessment criteria, the criteria were weighted and prioritized using AHP. Lai and Yik 
(2009) applied AHP to identify the significant indoor environmental quality areas in high-rise residential buildings. Specifically, AHP was used to derive importance weights for various indoor environmental quality attributes. Eweda et al. (2015) developed a condition assessment model for buildings. A new building asset hierarchy is proposed in which the space is the principle element of evaluation. AHP and ANP techniques were used to assign the relative weights to models' attributes.

\section{CALCULATION OF THE REQUIRED SAMPLE SIZE}

According to Bartlett et al. (2001), the required sample size for unlimited population can be calculated as follow in equation (1):

$$
\mathrm{n}=\frac{\mathrm{K}^{2} * \mathrm{P} *(1-\mathrm{P})}{\mathrm{E}^{2}}
$$

Where $\mathrm{n}$ is the required sample size for finite population, $\mathrm{K}$ value equals to 1.645 when confidence level equals to $90 \%, \mathrm{P}$ is the proportion of population i.e. $\mathrm{P}$ is the variance degree between the population (the critical value of $\mathrm{P}$ is 0.5 ), $\mathrm{E}$ is the acceptable margin of error $=10 \%$ for confidence $90 \%$. By substituting of these parameters in the above Equation, the minimum sample size for the respondents of this research for infinite population is 68. In this research, eighty experts have participated in filling the questionnaires. This proves that the number of experts is representative to the population.

\section{PROBLEM STATEMENT}

In Egypt, all governmental schools' maintenance is under responsibility of General Authority for Educational Buildings (GAEB). The inspection and maintenance reports for these schools are performed manually and lead to inefficient maintenance processes. Also, the funds assigned to educational facilities buildings are limited to maintain the all buildings that need to raise their efficiency. So, it is necessary to identify and assess the criteria affecting physical condition of these buildings.

Management and operation of educational buildings contribute significantly to the formation of a healthy and living environment for educational building users. Lack of funds and mismanagement are from the main reasons causing unacceptable performance of building facilities. Maintaining a building is essential to keep it performing and functioning for a longer period of time, and condition assessment is the most important stage during the asset management process. It is the starting point for prioritizing defects that is necessary to repair, rehabilitate or replace any component in the building (Eweda 2012).

\section{RESEARCH OBJECTIVES}

The main objectives of this paper are: (1) to calculate the RWs of each related and unrelated criterion associated to the educational buildings through using the well-known techniques (AHP and ANP), (2) to help the project and facility managers to use the most important factors for assessing the physical condition of the educational buildings, (3) and to provide a basis for reducing the cost of maintenance and repair through increasing the useful life for the materials and tools for the most important criteria during setting the preconstruction specifications.

\section{RESEARCH METHODOLOGY}

The research methodology is divided into 13 steps as shown in Figure 1. In Step 1, literature review was conducted to identify and structure the criteria that is the most important task through the asset management scheme. These criteria can be assessed thereafter to estimate their RWs that represent the initial point for the decision-making process. 
Abdelazeem S. Abdelazeem, Ahmed H. Ibrahim and Mohamed S. Mohamed

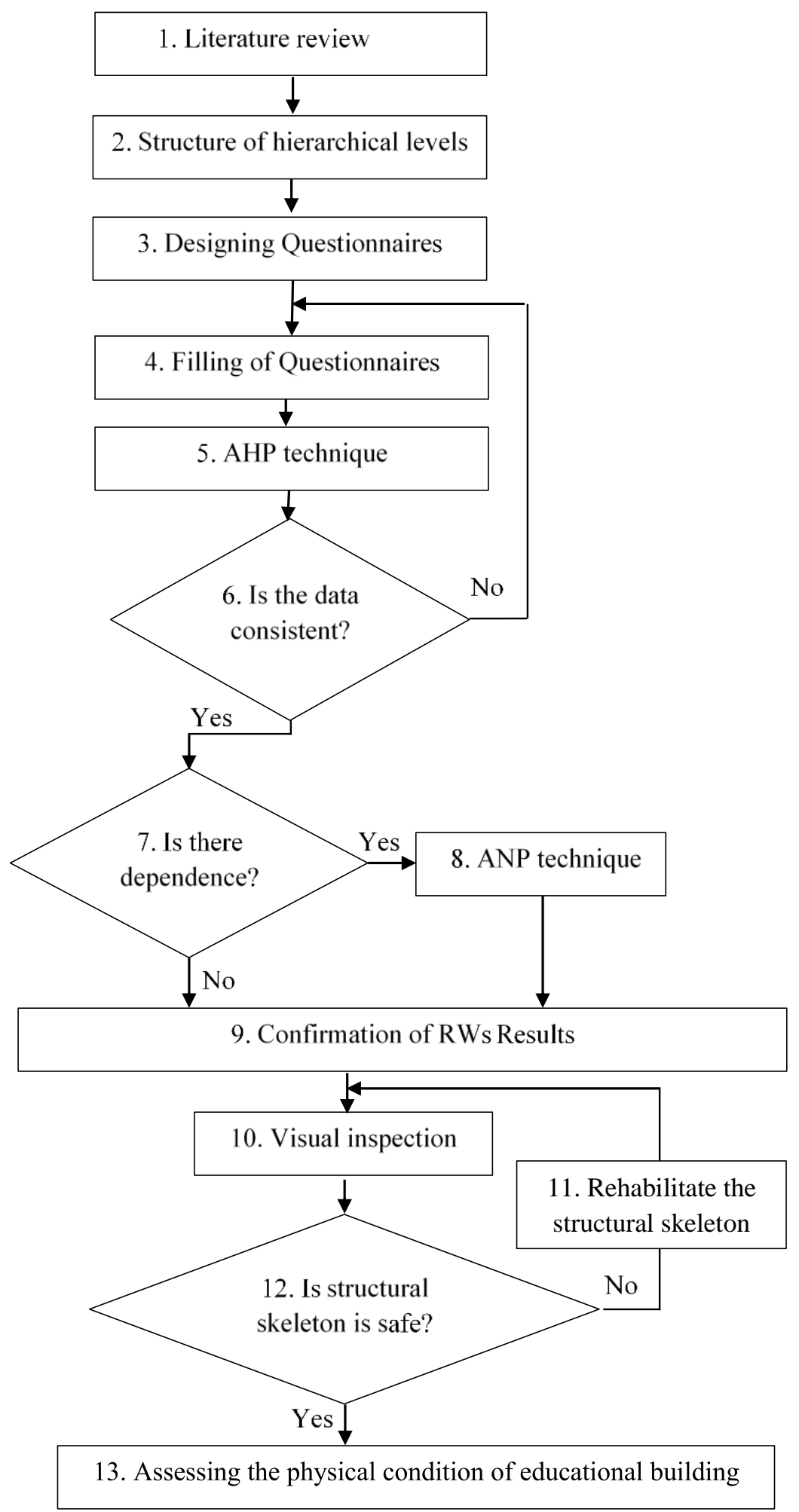

Figure 1 The framework of the proposed research

In Step 2, the educational building is divided into closed and open areas. The educational building is structured in hierarchical way to design the questionnaires. Fig. 2 shows the educational building hierarchy structure and its main six levels: (1) educational school; (2) closed and open areas; (3) spaces inside the building and façade and their level ranking; (4) spaces level ranking; (5) building category level ranging; (6) and family level ranking. 
In Step2, the building components under different categories should be classified, like dividing the building into different disciplines such as electrical (Elect), architectural (Arch.), and mechanical (Mech.), and which can be divided into families (windows, exterior doors, ceilings, and so on).

In Step 3, data collection includes eight questionnaires filled from eighty experts via direct interview. Eighty experts include facilities managers, architects, condition assessment consultants, and asset management consultants were asked to direct contact (Step 4). The questionnaires' responses are analyzed in Excel file and used to calculate the RWs of criteria and sub-criteria. In Step 5, the main function of AHP in the system was to obtain the variables' structure and determine the variables' respective weights. AHP was used to weight different indexes

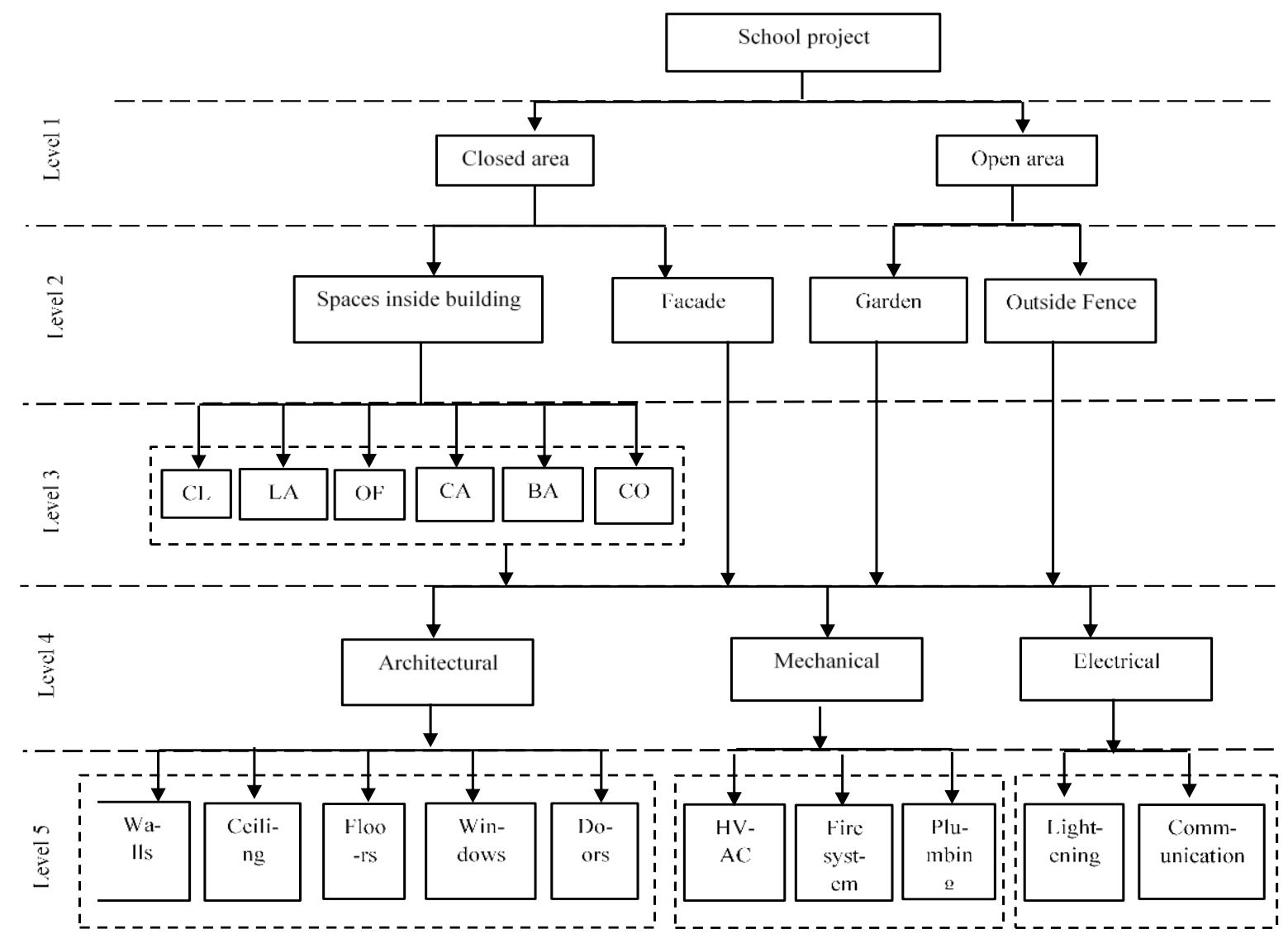

Figure 2 The five main levels of an educational building hierarchy

Pair-wise comparison or judgment matrices are prepared to calculate the relative importance values that are determined by using the (Saaty 1980) on scale ranged from 1 to 9 , as indicated in Table 1.

Table 1 Pair-wise comparison scale (Saaty 1980)

\begin{tabular}{ll}
\hline Option & Numerical value(s) \\
\hline Equal & 1 \\
Marginally strong & 3 \\
Strong & 5 \\
Very strong & 7 \\
Extremely strong & 9 \\
Intermediate values & $2,4,6,8$ \\
\hline
\end{tabular}


The elements of pairwise matrix A were normalized as follow in equation (2):

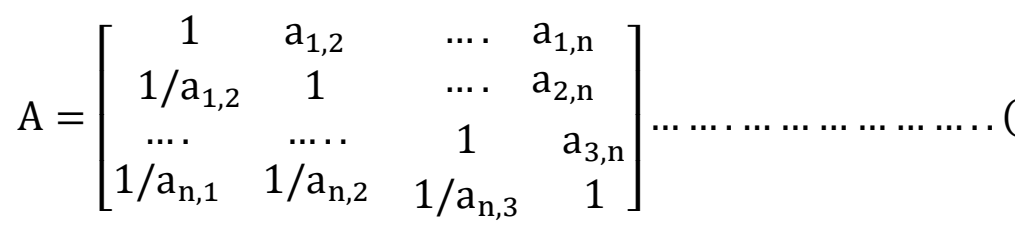

The average of judgment matrix A for eighty responses is calculated as follow in equation (3):

$$
\mathrm{a}_{\mathrm{ij}}=\frac{\sum_{\mathrm{i}=1}^{80} \mathrm{r}_{\mathrm{i}}}{\mathrm{N}}
$$

Where $\mathrm{N}$ is the number of respondents $(\mathrm{N}=80)$. The sum of row vector in the judgment matrix $\mathrm{A}$ is calculated as follow in equation (4):

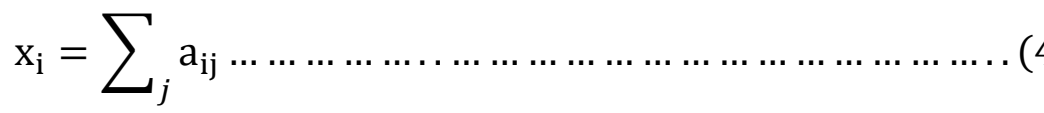

The relative weight $\mathrm{RW}_{\mathrm{i}}$ are calculated as follow in equation (5):

$$
\mathrm{RW}_{\mathrm{i}}=\frac{\mathrm{x}_{\mathrm{i}}}{\sum_{i} \mathrm{x}_{i}}
$$

Table 3 presents the calculation of the RWs for the building category using AHP technique. The consistency index (CI) was defined according to (Saaty 1980), and it decreases proportionally with the consistency of the matrix as indicated in Table 2.

Table 2 Consistency Index (Noble and Sanchez 1993)

\begin{tabular}{llllllllll}
\hline $\mathrm{n}$ & 1 & 2 & 3 & 4 & 5 & 6 & 7 & 8 & 9 \\
\hline $\mathrm{RI}$ & 0 & 0 & 0.49 & 0.82 & 1.03 & 1.16 & 1.25 & 1.31 & 1.36 \\
\hline $\mathrm{n}$ & 10 & 11 & 12 & 13 & 14 & 15 & & & \\
\hline $\mathrm{RI}$ & 1.39 & 1.42 & 1.44 & 1.46 & 1.48 & 1.49 & & & \\
\hline
\end{tabular}

In Step 6, it is necessary to evaluate the reliability of the obtained RWs through measuring the inconsistency of judgment matrix A: The inconsistency increases if the experts' judgments are badly posed. At this point, it is necessary to evaluate the reliability of the obtained RWs through measuring the inconsistency of matrix A: The inconsistency increases if the experts' judgments are badly posed. In the approximate method, the principal eigenvalue for the judgment matrix is approximately evaluated as follow in equation (6) (Ishizaka and Lusti 2006):

$$
\lambda \max =\sum_{i=1}^{n} \frac{\lambda \max _{i}}{n}
$$

Where $\mathrm{n}$ is the number of criteria, $\lambda \max _{i}=\mathrm{RW}_{\mathrm{i}} * \mathrm{a}_{\mathrm{ij}}$. Then, the consistency index (CI) is defined according to Saaty (1980), and it decreases proportionally with the consistency of the pairwise matrix as follow in equation (7):

$$
\mathrm{CI}=\frac{\lambda \max -\mathrm{n}}{\mathrm{n}-1}=\frac{3.0161-3}{3-1}=0.008
$$

To provide a measure of the inconsistence that is independent of the matrix order, Saaty (1980) proposed the consistency ratio (CR). Table 4 presents the value of $\lambda$ max and the consistency index $(\mathrm{CI})$. This is obtained by considering the ratio between $\mathrm{CI}$ and its expected value [random consistency index (RI)] determined over a large number of positive reciprocal matrices of order $\mathrm{n}$, as follow in equation (8):

$$
\mathrm{CR}=\frac{\mathrm{CI}}{\mathrm{RI}(\mathrm{n})}=\frac{0.008}{0.49}=0.016
$$


Based on numerous empirical studies, (Saaty 1980) determined that the value of CR is 0.016 (less than 0.10) and it is satisfactory (Step 9). Such a test about CR is crucial for establishing the reliability of assigned judgments, and it is the parameter that mathematically determines the incoherence of the decision-maker judgments.

Table 3 Calculation of the RWs for the building category using AHP technique

\begin{tabular}{llllll}
\hline & Arch. & Mech. & Elect. & $\mathrm{x}_{\mathrm{i}}$ & $\mathrm{RW}_{\mathrm{i}}$ \\
\hline Arch. & 1.0000 & 6.2000 & 6.7000 & 13.900 & 0.7564 \\
Mech. & 0.1613 & 1.0000 & 1.5000 & 2.6613 & 0.1448 \\
Elect. & 0.1493 & 0.6667 & 1.0000 & 1.8159 & 0.0988 \\
\hline Sum & 1.3105 & 7.8667 & 9.2000 & 18.3772 & 1.0000 \\
\hline
\end{tabular}

Table 4 The consistency index (CI)

\begin{tabular}{lllllll}
\hline & Arch. & Mech. & Elect. & $\mathrm{RW}_{\mathrm{i}}$ & $\mathbf{x}_{\mathbf{i}}$ & $\lambda \max _{i}$ \\
\hline Arch. & 0.7564 & 0.8979 & 0.6621 & 0.7564 & 2.3163 & 3.0622 \\
Mech. & 0.1220 & 0.1448 & 0.1482 & 0.1448 & 0.4150 & 2.8662 \\
Elect. & 0.1129 & 0.0965 & 0.0988 & 0.0988 & 0.3082 & 3.1199 \\
\hline \multicolumn{7}{c}{$\lambda \max$} \\
\hline
\end{tabular}

\section{AHP FOR IDENTIFYING BUILDING CATEGORIES RWS}

From the survey questionnaire of prioritizing spaces inside and outside view of a building, it was demonstrated that each space type has its particular relative weight, which depends on the purpose of the space. Several researches have studied the complicated relationships between the building categories (Elhakeem 2005; Langevine 2006; Ahluwalia 2008). Each of these researches calculated the RWs for the building categories through the building hierarchy. In the present research, the RWs of these categories inside each space and the changes from one space type to another have been determined. For example, the RWs of a ceiling in classrooms space is different than its RWs in other spaces like laboratories or offices. Also, the RWs of building categories inside the space is different than its RWs in other space types. Therefore, this research will identify the RWs of each building category inside each specific space type. All the spaces with the same type will have the same RW of building categories. A pair-wise or judgment comparison is made to identify the RW of each building category with respect to another inside of a specific space type (Eweda 2015).

In Step 7, it is necessary to take the interrelationships between the building categories (Arch., Mech., and Elect.) in consideration. ANP technique was chosen to calculate the RWs of each building category inside a space type (W:Catji) using the ANP Super-matrix; this is because the ANP as indicated in Figure 3 and illustrated below to classroom space type as example. Table 5. Presents the inner dependence matrix of building category with respect to "Architectural". Also, Table 6 presents the inner dependence matrix of building category in classrooms with respect to "Mechanical". Moreover, Table 7 presents the inner dependence matrix of building category in classrooms with respect to "Electrical". The three tables are collectively are used to presents the RWs in Table 8. 
Abdelazeem S. Abdelazeem, Ahmed H. Ibrahim and Mohamed S. Mohamed

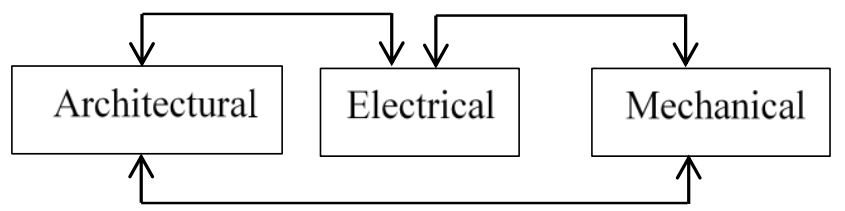

Figure 3 The interrelationships between building categories

Table 5 The inner dependence matrix of building category in classrooms with respect to

"Architectural"

\begin{tabular}{lllll}
\hline & Mechanical & Electrical & Sum & $\mathrm{RW}_{\mathrm{i}}$ \\
\hline Mechanical & 1.00 & 1.50 & 2.50 & 0.60 \\
Electrical & 0.67 & 1.00 & 1.67 & 0.40 \\
\hline & & & 4.17 & 1.00 \\
\hline
\end{tabular}

Table 6 The inner dependence matrix of building category in classrooms with respect to "Mechanical"

\begin{tabular}{lllll}
\hline & Architectural & Electrical & Sum & $\mathrm{RW}_{\mathrm{i}}$ \\
\hline Architectural & 1.00 & 6.70 & 7.70 & 0.87 \\
\hline Electrical & 0.15 & 1.00 & 1.15 & 0.13 \\
\hline & & & 8.85 & 1.00 \\
\hline
\end{tabular}

Table 7 The inner dependence matrix of building category in classrooms with respect to "Electrical"

\begin{tabular}{lllll}
\hline & Architectural & Mechanical & Sum & $\mathrm{RW}_{\mathrm{i}}$ \\
\hline Architectural & 1.00 & 6.20 & 7.20 & 0.86 \\
\hline Mechanical & 0.16 & 1.00 & 1.16 & 0.14 \\
\hline & & & 8.36 & 1.00 \\
\hline
\end{tabular}

\section{ANP FOR IDENTIFYING BUILDING CATEGORIES RWS}

Table. 8 presents the families of the three categories of a building. The building categories and their grouped decomposed families. The connections between the building categories indicate the flow of influence between the elements. For example, the connection between any two categories indicates that one relationship is exited between two elements in those two categories. By Knowing the RW of each space inside the building, the RW of each building category inside each space and the RW of each family inside each building category.

Table 8 The relative weight for building categories of class rooms using ANP technique

\begin{tabular}{lllllll}
\hline & Architectural & Mechanical & Electrical & $\begin{array}{l}\text { RW } \\
\text { (AHP) }\end{array}$ & $\begin{array}{l}\text { RW } \\
\text { (ANP) }\end{array}$ \\
\hline Architectural & 1.00 & 0.87 & 0.86 & $76 \%$ & 0.97 & $48 \%$ \\
Mechanical & 0.60 & 1.00 & 0.14 & $14 \%$ & 0.61 & $31 \%$ \\
Electrical & 0.40 & 0.13 & 1.00 & $10 \%$ & 0.42 & $21 \%$ \\
\hline & & & & & 2.00 & 1.00 \\
\hline
\end{tabular}

AHP technique was used to calculate the RWs of the spaces inside and outside view of a building. As shown in Figure 3, the classroom space type that includes most of the education processes had the highest relative weight $(\mathrm{RW}=26.76 \%)$ followed by the bathrooms $(\mathrm{RW}=26.14 \%)$ and corridors and stairs $(\mathrm{RW}=25.77 \%)$. On the other hand, the cafeteria space type was the least relative weight $(\mathrm{RW}=1.58 \%)$ among all other space types. AHP and ANP 
techniques were both used to calculate the RWs of the building categories. ANP technique provided an improved approach to assess building categories' relative weights for the spaces inside and outside view of a building.

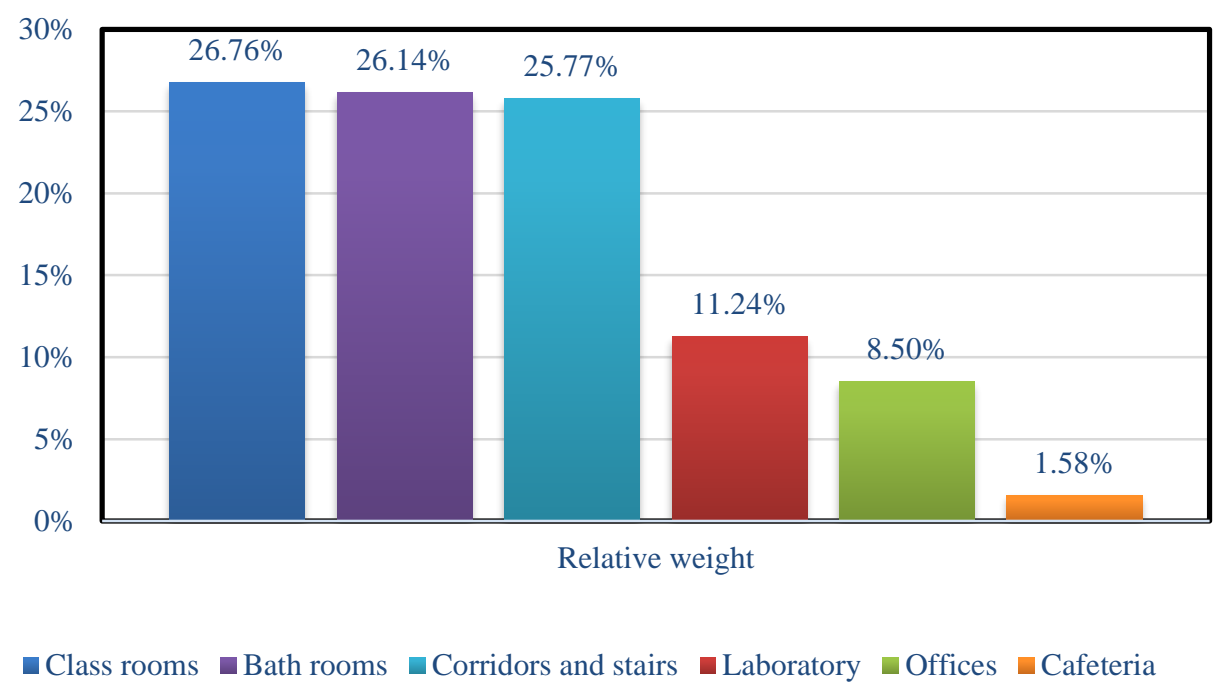

Figure 3 The RWs of spaces in Level 3 calculated using AHP technique

It is concluded from Figure 4 that it is observed in classrooms spaces that the appearance of the architectural elements was higher than those of the electrical and mechanical due to the function of the architectural elements that are mainly used as the final finish covering a lot of pipes, connections, cables, and so on, and their appearance is an important role. Also, as shown in Figure 4, the RWs of the mechanical system is higher than architectural in laboratory spaces; this can be explained as it is so critical to have any problems in the laboratory mechanical system in a laboratory that is hosting activities such as chemical reactions or biological experiments that may cause steams and gases. There its performance for sealing the building from the outer climate is more important. On the other hand, it is observed that the performances of the mechanical elements are the most important when compared with the other criteria. This is because they are mostly hidden behind the walls and ceilings.

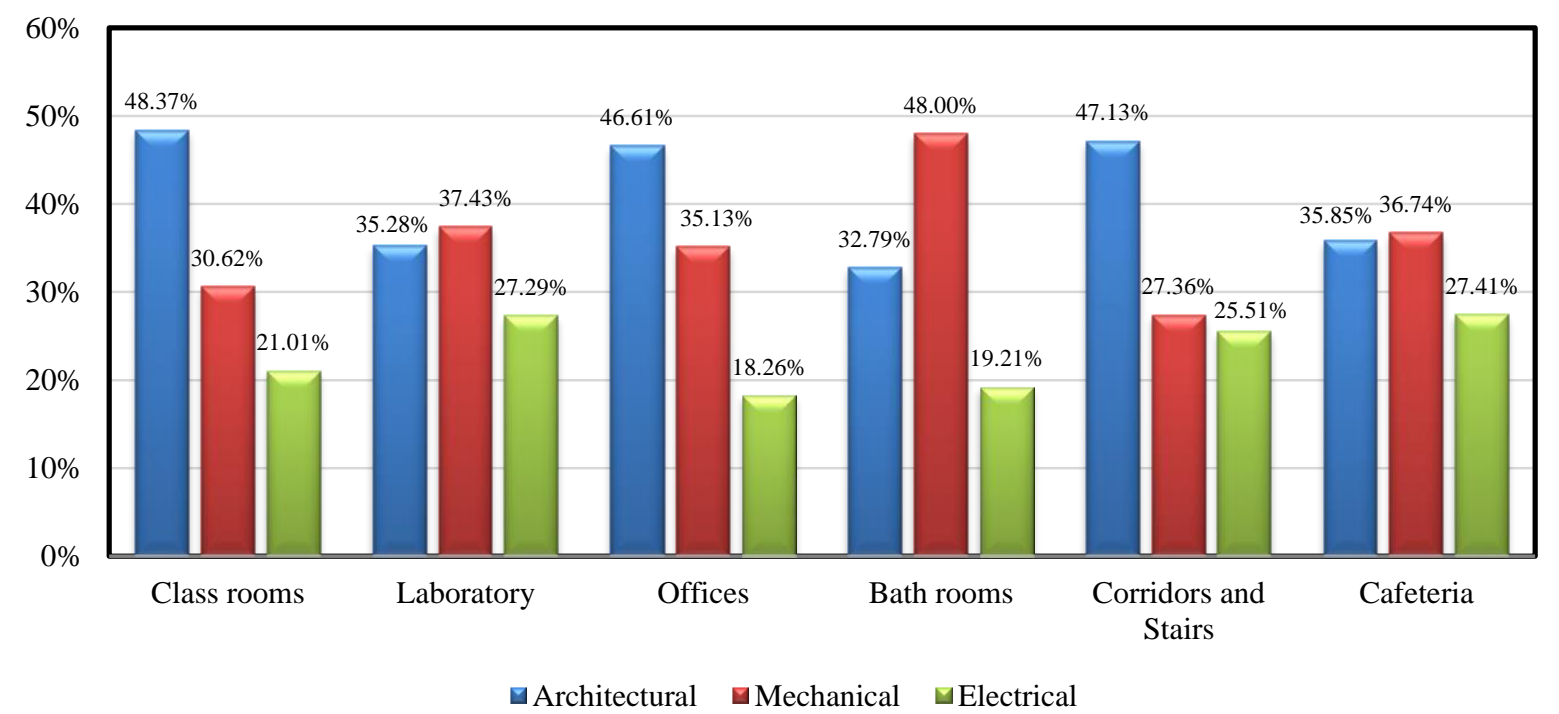

Figure 4 The RWs of building category in each space calculated using ANP technique 
According to the responses of the experts for calculating the RWs of the physical components, the RWs varies from a space to another that proves the assumption of the effect of the nature of the space type on the importance of all families that are inside it. Also, there is no expert who neglected the priority of each space type and no expert stated that all spaces types inside a building are equally important.

\section{CALCULATIONS OF FAMILY DECOMPOSED WEIGHTS}

The family decomposed weight for $\left(\mathrm{FWD}_{\mathrm{SP}}\right)$ inside a space is used to calculate the RW of each decomposed family in the entire educational building, which shows how important is the condition of each family and how it gives the physical building condition. The FWD SPi $_{\text {in }}$ each space can be calculated as follow in equation (9):

$$
\mathrm{FWD}_{\mathrm{SPi}}=\mathrm{W}_{\mathrm{SPi}} \times \mathrm{W}_{\mathrm{Catj}} \times \mathrm{W}_{\text {Fam }}
$$

The family decomposed weights entire a building $\left(\mathrm{FWD}_{\mathrm{BDi}}\right)$ can be calculated as follow in equation (10):

$$
\mathrm{FWD}_{\mathrm{BDi}}=\mathrm{W}_{\mathrm{AT}} \times \mathrm{W}_{\mathrm{ST}} \times \mathrm{FWD}_{\mathrm{SPi}}
$$

Where $\mathrm{W}_{\mathrm{AT}}$ is the relative weight for an area type, $\mathrm{W}_{\mathrm{ST}}$ is the relative weight for a space type.

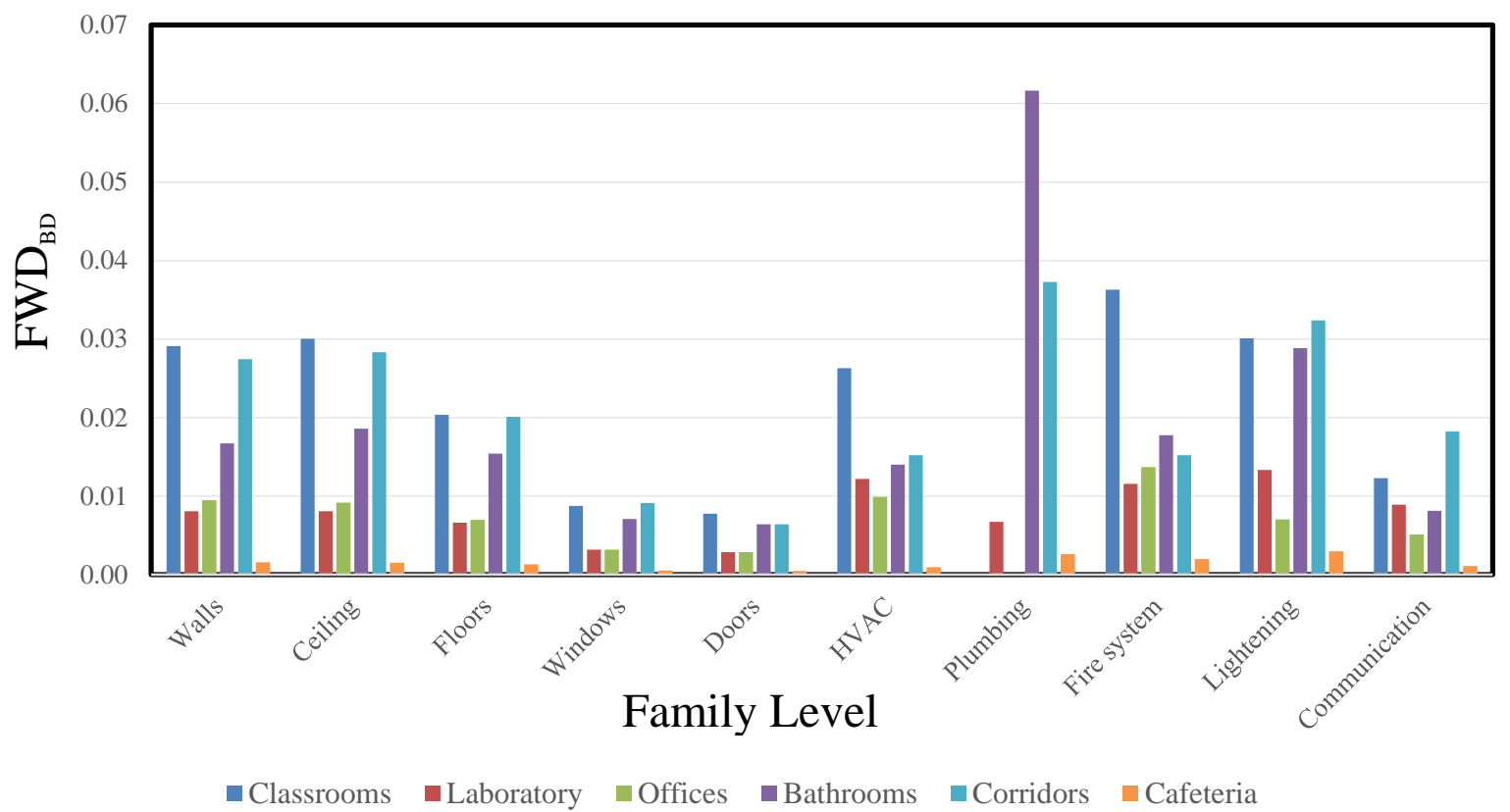

Figure 5 The family decomposed weights entire an educational building

During Calculating of the family decomposed weight (FWD $\mathrm{FDi}_{\mathrm{B}}$ ) of each building category inside the educational building, it was found that the effect of the high RW of a space type such as the classroom is significant; it results to a high relative weight for all the decomposed relative weights of the categories inside it. Also, it is concluded that the all the criteria in the attribute level are the most important in classrooms and corridors spaces. The ceiling, floors, and windows are the most important in the classrooms, corridors, and bathrooms. The doors are the most important criteria in the classrooms, bathrooms, and corridors. HVAC tasks which are heating, ventilating, and air conditioning; are the most important criteria in the classrooms, corridors, and bathrooms. Also, the plumbing is the most important in the bathrooms and corridors. The fire system task is the most important in the classrooms, bathrooms, and 
corridors. Lightening task is the most important criteria in the corridors, classrooms, and bathrooms spaces. Communication is the most important criteria in the classrooms, corridors, and laboratory spaces.

\section{CONCLUSIONS AND RECOMMENDATIONS}

Identifying the most important criteria affecting the physical condition of an educational building is the first step to plan for maintenance and repair works. An assessment of the relative weights of educational building is developed based on the space internal physical components. The first objective of this paper is to identify the criteria affecting the physical condition of an educational building and calculate its RWs using the well-known techniques (AHP and ANP). The second is to use the most important criteria for assessing the physical condition of the educational buildings. The third is to provide a basis fair reducing maintenance costs for increasing the useful life for the materials and tools for the most important criteria during setting the preconstruction specifications. Identifying the most important criteria affecting the physical condition also helps to identify, locate, and diagnose building problems and assist in the building maintenance decision-making process.

A building hierarchy is proposed to assess RWs of elements in an educational building. A survey questionnaire was designed and sent to eighty facility managers and experts in Egypt. Analytical hierarchy and network (AHP and ANP) processes were both used to calculate the relative weights of all the element inside the building hierarchy. ANP provided an effective approach to assess building components' relative weights inside building categories like architectural, electrical, and mechanical works. The data analysis proved that the RWs of spaces vary in accordance with building type. In addition to the building categories and subcategories, weights are different from one space type to another, which proves the hypothesis that a space's function and the tasks conducted within it affect its importance as well as the physical components inside. It is concluded that the classroom space type that includes most of the education processes had the highest relative weight $(\mathrm{RW}=26.76 \%)$ followed by the bathrooms $(\mathrm{RW}=26.14 \%)$ and corridors and stairs $(\mathrm{RW}=25.77 \%)$. In addition to the building categories and subcategories, weights are different from one space type to another, which proves that a space's function and the tasks conducted within it affect its importance. Last but not least, AHP and ANP techniques provided an improved approach to calculate the RWs of each criterion affecting physical condition of educational building in Egypt.

\section{REFERENCES}

[1] Abudayyeh, O.; Zidan, S. J.; Yehia, S., Randolph D. 2007. "Hybrid prequalification-based, innovative contracting model using AHP.” J. Manage. Eng. 23(2):88-96.

[2] Ahluwalia, S. S. (2008). "A framework for efficient condition assessment of the building infrastructure." Ph.D. thesis, Univ. of Waterloo, Waterloo, ON, Canada.

[3] Ahmad I, Azhar, S., Lukauskis, P. 2004. "Development of a decision support system using data warehousing to assist builders/developers in site selection." Automat Constr. 13 (4):525-542.

[4] Ali, H. H.; and Al-Nsairat, S.F. (2009). "Developing a green building assessment tool for developing countries-case of Jordan.” Build Environ. 44(5):1053-1064.

[5] Azimi, R.; Chamzini, A. Y.; Modares, T.; Zavadskas, E. K. (2011). "Ranking the strategies of mining sector through ANP and TOPSIS in a SWOT framework" Journal of Business Economics and Management. DOI: 10.3846/16111699.2011.626552.

[6] Bartlett, j. E., Kotrlik, W. and Higgins, C. (2001). "Organizational research: determining appropriate sample size in survey research." Learning and Performance Journal, 19(1), 43-50. 
[7] Barzilai, J., Cook, W. D., and Golany, B. (1987). "Consistent weights for judgments matrices of the relative importance of alternatives.” Oper. Res. Lett., 6(3), 131-134.

[8] Clift, M.; and Butler, R. (1995). "The Performance and Cost-inuse of Buildings: A New Approach.” BRE Report, Building Research Establishment, Garston, 3.

[9] Cronbach, L. J. (1951). "Coefficient alpha and the internal structure of tests." Psychometrika, 16(3), 297-334.

[10] Darko, A., Chan, A. P. C., Ameyaw, E. E., Owusu, E. K., Pärn, E., \& Edwards, D. J. (2019). "Review of application of analytic hierarchy process (AHP) in construction." International journal of construction management, 19(5), 436-452.

[11] Douglas; J., (1996). "Building performance and its relevance to facilities management". Facilities, Volume 14, Numbers 3/4, March/April 1996, pp. 23-32

[12] El_Sayegh, S. M. 2009. "Multi_criteria decision support model for selecting the appropriate construction management at risk firm." Constr. Manage. Econ. 27(4):385-398.

[13] El-Anwar O, Chen L. 2013. "Computing a displacement distance equivalent to optimize plans for post disaster temporary housing projects.” J. Constr. Eng. Manage. 139(2):174- 184.

[14] Elhakeem, A. A. M. (2005). "An asset management framework for educational buildings with life-cycle cost analysis." Ph.D. thesis, University of Waterloo, Waterloo, Canada.

[15] Elhakeem, A., \& Hegazy, T. (2005, June). Towards a visual guidance system for condition assessment of the building infrastructure. In Proceedings of 1st CSCE Specialty Conference on Infrastructure Technologies, Management, and Policies, CSCE, Toronto, Ontario, Canada, June (pp. 2-4).

[16] El-Sawalhi N, Eaton D, Rustom R. 2007. "Contractor pre-qualification model: state-of-the-art." Int. J. Proj. Manage. 25 (5):465-474.

[17] Eweda, A. (2012). "An Integrated Condition Assessment Model for Educational Buildings Using BIM.” Doctoral dissertation, Concordia University.

[18] Eweda, A.; Zayed, T.; and Alkass, S. (2015). "Space-based condition assessment model for buildings: case study of educational buildings" Journal of Performance of Constructed Facilities, ISSN 0887-3828/04014032(12).

[19] Görener, A. (2012). "Comparing AHP and ANP: an application of strategic decisions making in a manufacturing company.” International Journal of Business and Social Science, 3(11), 194208.

[20] Hudson, W. R., Haas, R. C. G., and Uddin, W. (1997). Infrastructure management: Integrating design, construction, maintenance, rehabilitation, and renovation, McGraw-Hill, New York.

[21] Hyun C.; Cho, K.; Koo, K., Hong, T.; Moon, H. (2008). "Effect of delivery methods on design performance in multifamily housing projects." J. Constr. Eng. Manage. 134(7):468-482.

[22] Ishizaka, A., and Lusti, M. (2006). "How to derive priorities in AHP: A comparative study." Cent. Eur. J. Oper. Res., 14(4), 387-400.

[23] Johnson, R. E., and Clayton, M. J. (1998). "The impact of information technology in design and construction: The owner's perspective.” Autom. Constr., 8(1), 3-14.

[24] Lai JH, Yik FW. (2009). "Perception of importance and performance of the indoor environmental quality of high-rise residential buildings." Build Environ. 44(2):352-360.

[25] Langevine, R. (2006). "A decision support system for the maintenance management of buildings." Ph.D. thesis, Univ. of Alberta, Edmonton, AB, Canada. 
[26] Langevine, R. (2006). "A decision support system for the maintenance management of buildings." Ph.D. thesis, Univ. of Alberta, Edmonton, AB, Canada.

[27] Lee, J., Edil, T. B., Benson, C. H., \& Tinjum, J. M. (2013). Building environmentally and economically sustainable transportation infrastructure: green highway rating system. Journal of Construction Engineering and Management, 139(12), A4013006.

[28] Lee, J.; Edil, T. B. ; Benson, C. H.; and Tinjum, J. M. (2013). "Building Environmentally and Economically Sustainable Transportation Infrastructure: Green Highway Rating System." Journal of Construction Engineering and Management, Volume 139(12), DOI: 10.1061/19437862.0000742 .

[29] Mahdi IM, Al-Reshaid K, Fereig SM. 2006. "Optimum house delivery decision model from the government's and recipients' point-of-view.” Eng. Constr. Archit. Manage. 13(4):413- 430.

[30] Rugless, J. (1993). “Condition assessment surveys.” Facil. Eng. J., 21(3),11-13.

[31] Ruiz M. C.; Romero E, P.;_Erez, M. A.; Fern_andez I. (2012). "Development and application of a multi-criteria spatial decision support system for planning sustainable industrial areas in Northern Spain.” Automat. Constr. 22:320-333.

[32] Saaty, T. L. (1980). The analytical hierarchy process: Planning, priority setting, resource allocation, McGraw-Hill, London.

[33] Saaty, T. L. (1996) "Decision Making with Dependence and Feedback: The Analytic Network Process.” RWS Publications, Pittsburgh.

[34] Saaty, T. L., \& Vargas, L. G. (2012). "The seven pillars of the analytic hierarchy process." In Models, methods, concepts \& applications of the analytic hierarchy process (pp. 23-40). Springer, Boston, MA.

[35] Sangiorgio, V.; Uva, G.; and Fatiguso, F. (2018). "Optimized AHP to overcome limits in weight calculation: building performance application.” J. Constr. Eng. Manage., 144(2): 04017101.

[36] Schneider, M. (2002). Do school facilities affect academic outcomes? Washington, DC: National Clearinghouse for Educational Facilities.

[37] Sha K, Yang J, Song R. (2008). “Competitiveness assessment system for China's construction industry. Build Res Inf., 36 (1), 97-109.

[38] Sharma, M. J., Moon, I. and Bae, H. (2008), Analytic hierarchy process to assess and optimize distribution network, Applied Mathematics and Computation, 202, 256-265.

[39] Subramanyan, H.; Sawant, P. H.; and Bhatt, V. (2012). "Construction project risk assessment: development of model based on investigation of opinion of construction project experts from India.” J. Constr. Eng. Manage. 138(3):409-421.

[40] Topcu YI. 2004. A decision model proposal for construction contractor selection in Turkey. Build Environ. 39(4):469- 481.

[41] Tuzmen, S. and Sipahi, S. (2011), A multi-criteria factor evaluation model for gas station site selection, 2nd International Conference on Business and Economic Research (2nd ICBER 2011) Proceedings, pp. 601-610.

[42] Urquhart, T. (2006). Incorporating condition assessment into a comprehensive asset management program. Proceedings of the Water Environment Federation, 2006(8), 4198-4206.

[43] Uzarski, D. R., and Burley, L. A., Jr. (1997). "Assessing building condition by the use of condition indexes." Proc., 1997 Specialty Conf. on Infrastructure Condition Assessment: Art, Science, Practice, ASCE, Boston, MA, 365-374.

[44] Williams, B., "What a performance!” (Editorial), Property Management, 11, 190-91. (1993) 